\section{Gustatory cross adaptation between sweet-tasting compounds*}

\author{
DONALD H. McBURNEY† \\ University of Pittsburgh, Pittsburgh, Pennsylvania 15213
}

Taste profiles were obtained for 16 compounds after adaptation to sucrose, saccharin, and water. Sucrose adaptation reduced the sweetness of all sweet compounds. Saccharin adaptation, when analyzed over all compounds, also reduced sweetness, but the effect was less than that of sucrose. It is concluded that there may be a single receptor mechanism for the sweet quality. Adaptation to sucrose also increased the saltiness, sourness, and bitterness of the other compounds slightly. This increase should be attributed to the taste induced in water by adaptation to sucrose rather than a potentiation of the other compounds per se.

It is generally assumed that when adaptation of a receptor to one stimulus is followed by a decrease in the response to another stimulus, the receptor mechanisms coding the two stimuli are common. For taste, cross adaptation has been found to occur broadly between salty and sour compounds and between some, but not all, pairs of bitter compounds (McBurney \& Lucas, 1966; Smith \& McBurney, 1969; McBurney, Smith, \& Shick, 1972). These results imply that there is a single receptor mechanism for salty and sour qualities and two or more for the bitter quality. The present experiment was designed to extend these findings to the sweet quality.

\section{METHOD}

\section{Subjects}

Twenty nonsmokers, 11 females and 9 males, volunteered or were paid to serve as Ss. All were naive about the purpose of the study. One S's data indicated an obvious failure to follow instructions and so were not analyzed.

\section{Apparatus and Solutions}

All solutions were made with distilled water and maintained at $34^{\circ} \mathrm{C}$ in a water bath. The apparatus for temperature control and stimulus delivery was similar to that described by McBurney (1966). All stimuli but one were equated in total subjective intensity to $.1 \mathrm{M} \mathrm{NaCl}$ by nonmodulus magnitude estimation prior to the experiment. The stimulus that was not equated in subjective intensity was $.01 \mathrm{M} \mathrm{NaCl}$, which tastes sweet only at near-threshold concentrations. The stimuli were the following: $.0057 \mathrm{M}$

* Supported by USPHS Grant 5R01 NS 07873. I thank Carolyn Pratt for running the $S s$ and $T$. $R$. Shick and $S$. $L$. Buchner for assistance in analyzing the data. Linda Bartoshuk and $D$. V. Smith made a number of helpful suggestions concerning the experiment.

†Addres: 462 Langley Hall, University of Pittsburgh, Pittsburgh, Pennsylvania 15213. dulcin, $.7 \mathrm{M}$ dextrose, $.32 \mathrm{M}$ sucrose, $.32 \mathrm{M}$ fructose, $.25 \mathrm{M}$ maltose, $.9 \mathrm{M}$ lactose, .7 M glycerin, .75 M galatose, $.004 \mathrm{M}$ citric acid, $.1 \mathrm{M}$ caffeine, .4 M dl-alanine, $2.83 \mathrm{M}$ ethyl alcohol, $.01 \mathrm{M}$ $\mathrm{NaCl}, .01 \mathrm{M}$ saccharin, and $.008 \mathrm{M}$ calcium cyclamate. All but three are predominately sweet tasting. The others were chosen in order to include representatives of each of the four "basic tastes." The adapting solutions were distilled water, .32 M sucrose, and $.01 \mathrm{M}$ saccharin.

\section{Procedure}

The procedure and data collection were essentially the same as in McBurney et al (1972). The So were presented each of the 16 stimuli once under each of the three adapting conditions in each of two 1-h sessions. Order of adapting conditions was randomized. The adapting solution flowed for $2 \mathrm{~min}$ before the first stimulus and for $30 \mathrm{sec}$ before the was significant at the .05 level. others. The stimuli were presented in random order.

\section{RESULTS}

Each S's data were multipled by a constant so that the mean rating of all the stimuli after water adaptation was the same for each $S$. The arithmetic means of the sweetness ratings are shown in Fig. 1 for sucrose adaptation compared to adaptation to distilled water. The sweetness of all solutions was reduced by sucrose adaptation. The reduction was significant at the .05 level (two-tailed) for all solutions except caffeine, $.1 \mathrm{M} \mathrm{NaCl}$, and ethyl alcohol. These three solutions were the least sweet and thus could not very well have shown much reduction in sweetness. The reduction in sweetness caused by adaptation to saccharin is shown in Fig. 2. Eleven of the 16 compounds were less sweet after saccharin adaptation, whereas 5 were (slightly) sweeter. The difference in sweetness between saccharin adaptation and water adaptation was significant only in the cases of the reductions in saccharin, dulcin, and alanine.

The effects of sucrose and saccharin adaptation on the other qualities are not shown. These effects were small and apparently unsystematic. Those compounds and qualities that appeared to be affected significantly were not much more numerous than would be expected by chance from such a large number of comparisons. For this reason, the data were analyzed across all the compounds for the effect of sucrose and saccharin adaptation on the total intensity and the intensity of each quality. The

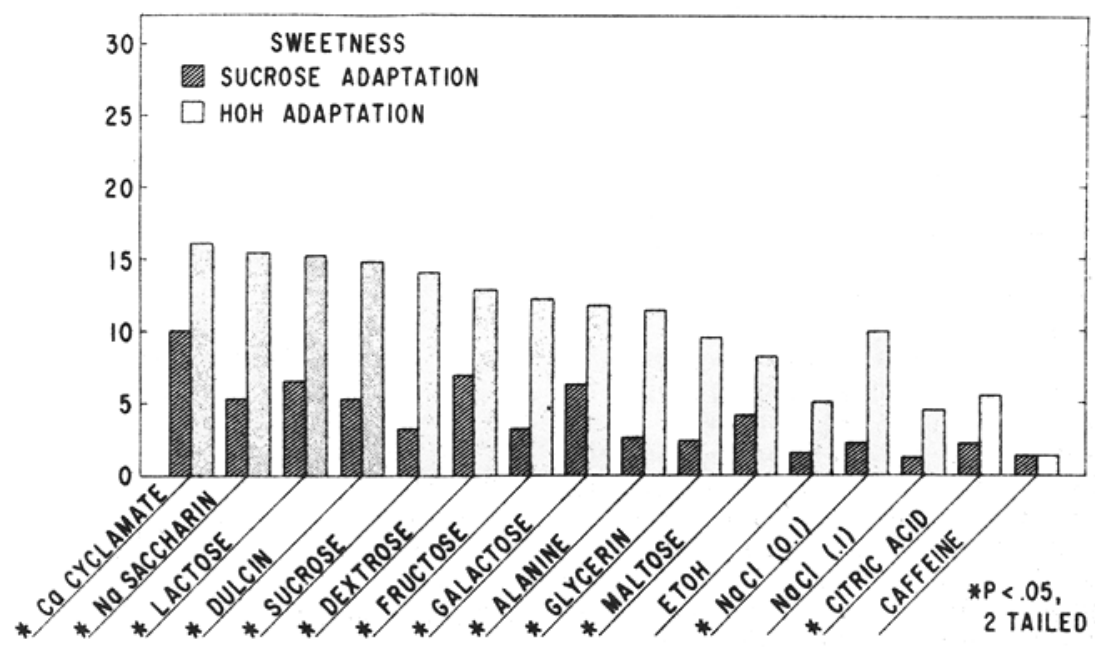

Fig. 1. Sweetness of the 16 compounds after adaptation to sucrose and after adaptation to water. Asterisks next to the name of a compound indicate that the difference in the sweetness of the compound under the two adapting conditions 


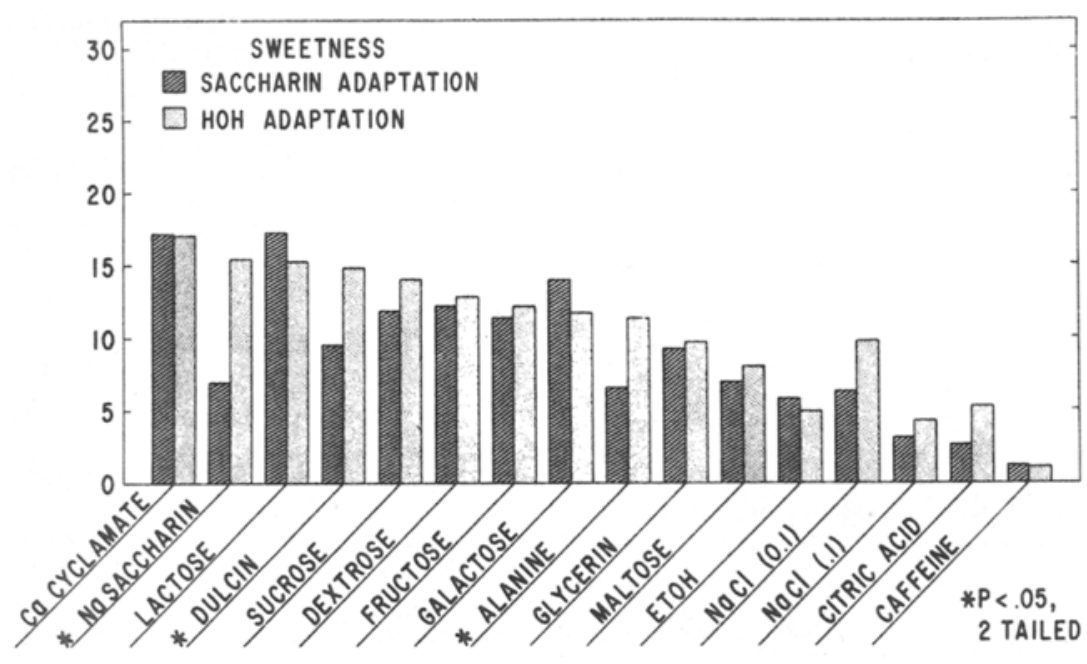

Fig. 2. Same as Fig. 1 but for saccharin adaptation.

results of this analysis are shown in Table 1. It may be seen that neither sucrose nor saccharin affected the overall intensity compared to water adaptation. As expected, sucrose adaptation reduced the sweetness of the compounds significantly $(p<.001)$. However, the effect of saccharin is also significant $(p<.05)$ when all compounds are considered together. In addition to these reductions, it may be seen that sucrose adaptation increased the saltiness $(p<.01)$, sourness $(p<.001)$, and bitterness $(p<.05)$ of the other compounds. All significance leveis are two-tailed.

\section{DISCUSSION}

We have now examined representatives of each of the "four basic taste qualities" and found that cross adaptation occurs for all tested compounds for the salty, sour, and sweet qualities. For the bitter quality, we found two groups of compounds within which cross adaptation occurred, but it did not always occur between groups. This implies that there are single mechanisms for salty, sour, and sweet but two or more for bitter.

These results also lend support for the notion of basic taste qualities for the three that showed cross adaptation, but, conversely, they also imply that bitter is not a simple taste quality. The notion of basic tastes has had a long evolution. Although there has been little recent discussion of this problem in the literature, there is still some uneasiness about the concept of basic tastes, as indicated by the tendency of authors to enclose the words "basic tastes" in quotation marks. If by receptor mechanism we mean receptor site, then it would seem the same (McBurney, 1966). Ano would be a case when adaptation was not complete; the second stimulus might be perceived as if it were simply a continuation of the first stimulus. A third case might be the presence of an aftertaste (not water taste) of the first stimulus that added to the taste of the second solution.

The first situation does not seem to be the case in the present experiment because the stimuli were matched for overall intensity before the experiment. The matching seems to have been quite successful. In addition, the important quality to consider is sweetness. Since saccharin is nearly pure sweet at this concentration and the others have other secondary taste qualities, saccharin had more sweetness than the others, except for lactose and cyclamate. The second and third possibilities have support in these data. Saccharin did not produce as complete adaptation as did sucrose. The sweetness of sucrose was reduced about $80 \%$ by sucrose adaptation, but saccharin adaptation reduced the sweetness of saccharin by $55 \%$. Finally, saccharin has a persistent aftertaste that may have contributed to the sweetness of the solutions that followed it. This effect would, of course, be directly opposite to the cross-adaptation effect.

Cross adaptation is sometimes said to produce an increase in the intensity of some compounds (Meiselman, 1968). In the present study, sucrose increased the intensity of the saltiness, sourness, and bitterness of the test compounds. This effect does not seem to be due to cross adaptation per se but to the closely related water-taste phenomenon. It has been demonstrated that adaptation to many compounds causes water to have a particular taste (McBurney \& Shick, 1971). McBurney and Bartoshuk conclude (1971) that when one compound is tasted after adaptation to another compound, the taste of the second compound is the sum of the taste of the second compound minus any cross-adaptation effect, plus the
Table 1

Means and F Ratios of the Taste Pxofiles Analyzed Across All Test Compounds for HOH Adaptation vs Adaptation to Sucrose or Saccharin

\begin{tabular}{|c|c|c|c|c|c|}
\hline & Total & Salty & Sour & Sweet & Bitter \\
\hline $\begin{array}{l}\text { Mean HOH } \\
\text { Adaptation }\end{array}$ & 30.30 & 4.99 & 6.25 & 10.25 & 8.73 \\
\hline $\begin{array}{l}\text { Mean Sucrose } \\
\text { Adaptation }\end{array}$ & 29.47 & 6.44 & 8.96 & 3.37 & 10.55 \\
\hline $\begin{array}{l}\text { F (Sucrose and } \\
\text { HOH Adaptation) }\end{array}$ & 1.11 & $8.28 * *$ & $16.90 t$ & 16.834 & $4.61 *$ \\
\hline $\begin{array}{l}\text { Mean Saccha- } \\
\text { rin Adaptation }\end{array}$ & 30.02 & 5.48 & 6.86 & 8.96 & 8.90 \\
\hline $\begin{array}{l}\text { F (Saccharin and } \\
\text { HOH Adaptation) }\end{array}$ & 0.18 & 1.04 & 1.06 & $4.94 *$ & 0.060 \\
\hline
\end{tabular}

$* p<.05, * * p<.01,+p<.001 ;$ all ps two-talled; $d f=1 / 558$ 
water taste that was induced by adaptation to the first compound. For example, sucrose produces a bitter-sour water taste. This bitter water taste sums with the bitter taste of caffeine to produce a potentiation of its bitterness. It is significant that the potentiation of the second compound by cross adaptation is not necessarily of the usual taste of the compound but is only of the taste that that particular adapting solution produces in water. The question remains as to why sucrose potentiated saltiness, sourness, and bitterness while it produced only a bitter or sour water taste. By collapsing the present data over all compounds, we obtain a more sensitive test of the water taste of a compound than when one counts frequency of occurrence of a taste in water. McBurney and Shick (1971) did not find sucrose to produce any water taste on more than $50 \%$ of the trial. MeBurney and Bogart (see McBurney, 1969) found that sucrose produced a significantly greater sour water taste compared to water adaptation. Bitterness was also increased in that experiment, but not significantly. In the McBurney and Shick experiment, partial correlations were obtained between the four taste qualities of the adapting solutions and the four qualities of the water taste. Sweetness showed small positive correlations with bitter, sour, and salty, in that order. It appears likely that sweet compounds, including sucrose, have a slight tendency to potentiate saltiness, but not enough to bring it above threshold.
Hahn (1949) found cross adaptation between some sweet compounds and not between others. In addition, he found basically the same sort of results for sour and bitter that we have found, but he failed to find adaptation between salty compounds. It is likely that the differences between his work and the present series of experiments are attributable to his use of threshold as the measure of cross adaptation. The water taste of the adapting solution and other qualities present in the test compound would be expected to interact in ways that would make it difficult to predict the effect of adaptation on the threshold.

Moskowitz found the magnitude functions of the sweetness of 15 sugars to have the same exponent, 1.3 (1970a), whereas three artificial sweeteners were found to have lower exponents that differed among them $(1970 b)$. It could be argued that this implies the existence of more than one site for the sweet taste. However, the artificial sweeteners have pronounced secondary tastes, particularly at higher concentrations. Moskowitz found the magnitude functions of total intensity of the taste of the artificial sweeteners to have different slopes and intercepts from those for sweetness alone. It seems more likely that the bitter secondary taste of these compounds acted like a mixture to reduce the sweetness of these compounds as seen by the intercepts of his functions. The reductions in slope can be attributed to the fact that the bitter quality increases faster than does the sweet taste as concentration increases until, at higher concentrations for saccharin, there is only a bitter taste.

\section{REFERENCES}

HAHN, H, Beitrage zur Reizphysiologie Heidelberz: Scherer, 1949.

MCBURNEY, D. H. Marnitude estimation of the taste of sodium chloride after adaptation to sodium chloride. Journal of Experimental Psychology, 1966, 72, 869-873.

MCBURNEY, D. H. Effects of adaptation on human taste function. In C. Ptaffmann (Ed.). Olfaction and taste. New Yoxk: Rock e feller University Press, 1969. Pp. 407-419.

MCBURNEY, D. H., \& BARTOSHUK, L. M Water taste in mammals. Paper presented at the Fourth International Symposium on Olfaction and Taste, Munich, 1971.

MCBURNEY, D. H., LUCAs, J. A. Gustatory cross adaptation between alls. Psychonomic Seience, 1966, 4, 301-302.

MoBURNEY, D. H., s sHCK, T. R. Taste and water taste of twenty-ix compounds for man. Perception Paychophyaics. 1971 10, 241-252.

MEBURNEY, D. H., SMITH, D. V., \& SHICK, T. R. Gustatory cross adaptation: Sournes and bitterness. Perception \& Psychophysics, 1972, 11, 228-232

MEISELMAN, $H$. L. Adaptation and cross adaptation of the four gustatory quillties. Perception \& Psychophysics, 1968, 4, 368-372.

MOSKOWITZ, H. R. Ratio scales of sugar sweetness. Perception \& Psychophysics. 1970a, 7, 315-320.

MOSKOWITZ, H. R. Sweetness and intensity of artificial sweeteners. Perception \& Psychophysics, 1970b, 8, 40-42.

SMITH, D. V., \& MCBURNEY, D. H. Gustatory cross-adaptation: Does a single mechanism code the salty taste? Journal of Experimental Psychology, 1969, 80, 101-105.

(Received for publication July 6, 1971.) 